\title{
Symmetry-Related Transitions in the Photoluminescence and Cathodoluminescence Spectra of Nanosized Cubic $\mathrm{Y}_{2} \mathrm{O}_{3}: \mathbf{T b}^{3+}$
}

\author{
Daniel den Engelsen, Paul G. Harris, Terry G. Ireland, ${ }^{\mathrm{z}}$ George Fern, and Jack Silver \\ Centre for Phosphor and Display Materials, Wolfson Centre for Materials Processing, Brunel University London, \\ Uxbridge, Middlesex UB8 3PH, United Kingdom
}

Herein the photoluminescence spectra of nanosized cubic $\mathrm{Y}_{2} \mathrm{O}_{3}: \mathrm{Tb}^{3+}$ having $\mathrm{Tb}^{3+}$ concentrations varying between 0.1 and 10 $\mathrm{Mol} \%$ are described. Low temperature cathodoluminescence spectra from these materials recorded in a scanning transmission electron microscope are presented and discussed. By studying the photoluminescence-spectra recorded at room temperature and focused on the ${ }^{5} \mathrm{D}_{4} \rightarrow{ }^{7} \mathrm{~F}_{5}\left(\mathrm{C}_{2}\right)$ and ${ }^{5} \mathrm{D}_{4} \rightarrow{ }^{7} \mathrm{~F}_{5}\left(\mathrm{C}_{3 \mathrm{i}}\right)$ transitions, at 542.8 and $544.4 \mathrm{~nm}$ respectively, it was found that the critical distance for energy transfer from $\mathrm{Tb}^{3+}$ ions at $\mathrm{C}_{3 \mathrm{i}}$ lattice sites to $\mathrm{Tb}^{3+}$ ions at $\mathrm{C}_{2}$ lattice sites was $1.7 \mathrm{~nm}$; at distances $>1.7 \mathrm{~nm}$, which prevail at low $\mathrm{Tb}^{3+}$ concentration, this energy transfer virtually stops. The gradual change of the excitation spectra upon increasing the $\mathrm{Tb}^{3+}$ concentration is also explained in terms of energy transfer from $\mathrm{Tb}^{3+}$ at $\mathrm{C}_{3 i}$ sites to $\mathrm{Tb}^{3+}$ at $\mathrm{C}_{2}$ sites. Cathodoluminescence spectra recorded at low temperatures with the scanning transmission electron microscope provided additional evidence for this radiationless energy transfer.

(C) The Author(s) 2015. Published by ECS. This is an open access article distributed under the terms of the Creative Commons Attribution 4.0 License (CC BY, http://creativecommons.org/licenses/by/4.0/), which permits unrestricted reuse of the work in any medium, provided the original work is properly cited. [DOI: 10.1149/2.0011512jss] All rights reserved.

Manuscript submitted July 23, 2015; revised manuscript received August 24, 2015. Published September 16, 2015.

Recently we published a study on the cathodoluminescence (CL) of nanosized cubic $\mathrm{Y}_{2} \mathrm{O}_{3}: \mathrm{Tb}^{3+}$ particles ${ }^{1}$ reference to this work will be made as Part 1. We identified a few peaks in the CL spectra that are related to $\mathrm{Tb}^{3+}$ at $\mathrm{C}_{3 \mathrm{i}}$ sites in cubic $\mathrm{Y}_{2} \mathrm{O}_{3}$ (the structure is that of the mineral bixbyite). In Part 1 , we have indicated the $\mathrm{C}_{3 \mathrm{i}}$ sites by $\mathrm{S}_{6}$. The vast majority of the spectral lines in the CL spectra of $\mathrm{Y}_{2} \mathrm{O}_{3}: \mathrm{Tb}^{3+}$ arise from $\mathrm{C}_{2}$ type transitions. We also found evidence that the two strongest emission lines in the ${ }^{5} \mathrm{D}_{4} \rightarrow{ }^{7} \mathrm{~F}_{5}$ transition cluster at $542.8 \mathrm{~nm}$ and $544.4 \mathrm{~nm}$ are split when recorded at low temperature. These spectral data provided insight into the energy flow from $\mathrm{Tb}^{3+}$ ions at $\mathrm{C}_{3 \mathrm{i}}$ lattice sites to $\mathrm{Tb}^{3+}$ ions at $\mathrm{C}_{2}$ lattice sites: the critical distance between a $\mathrm{Tb}^{3+}\left(\mathrm{C}_{3 \mathrm{i}}\right)$ donor ion and $\mathrm{Tb}^{3+}\left(\mathrm{C}_{2}\right)$ acceptor ion was found to be $1.7 \mathrm{~nm}$, which is about 5 times larger than the shortest distance between a cation at a $\mathrm{C}_{3 \mathrm{i}}$ site and a cation at a $\mathrm{C}_{2}$ site. ${ }^{1,2}$ It is the objective of the work described herein to gain more insight into the studies reported in Part 1 by measuring the photoluminescence (PL) spectra at room temperature and the CL spectra in a scanning transmission electron microscope (STEM) at low temperatures.

Many authors have reported on the PL spectrum of $\mathrm{Y}_{2} \mathrm{O}_{3}: \mathrm{Tb}^{3+}$; here we shall mention only the most relevant publications on the spectroscopic characteristics of $\mathrm{Y}_{2} \mathrm{O}_{3}: \mathrm{Tb}^{3+}$. An important result in Part 1 was the doublet structure of the $542 \mathrm{~nm}$ and $544 \mathrm{~nm}$ lines, which became noticeable at a temperature of $103 \mathrm{~K}$. A similar result was reported by Song and Wang, ${ }^{3}$ who also found 4 lines between 541 and $545 \mathrm{~nm}$ at $83 \mathrm{~K}$. At $274 \mathrm{~K}$ these lines coalesced into two peaks, in which the $542 \mathrm{~nm}$ peak still showed a shoulder. Najafov et al. ${ }^{4}$ showed the doublet structure of the $542 \mathrm{~nm}$ and $544 \mathrm{~nm}$ lines in the PL spectra of $\mathrm{Y}_{2} \mathrm{O}_{3}: \mathrm{Tb}^{3+}$ with various $\mathrm{Tb}^{3+}$ concentrations at room temperature. In the spectrum presented in their paper (Figure 5a) it can be observed that the height of the $544 \mathrm{~nm}$ doublet decreases with respect to the height of the $542 \mathrm{~nm}$ doublet upon increasing the $\mathrm{Tb}^{3+}$ concentration. Najafov et al. did not refer to these phenomena in their paper. $^{4}$

Concentration quenching was identified as an important issue in several publications on the PL spectrum of $\mathrm{Y}_{2} \mathrm{O}_{3}: \mathrm{Tb}^{3+}$. It was discussed by Najafov et al. ${ }^{4}$ and measured by Muenchausen et al. ${ }^{5}$ these latter authors found that the PL efficiency peaked at $0.5 \mathrm{Mol} \%$ in bulk $\mathrm{Y}_{2} \mathrm{O}_{3}: \mathrm{Tb}^{3+}$ material, whereas for their nano-material with particle size of $35 \mathrm{~nm}$ it peaked at $1.5 \% \mathrm{~Tb}^{3+}$. Wang et al. ${ }^{6}$ found that the ${ }^{5} \mathrm{D}_{4} \rightarrow{ }^{7} \mathrm{~F}_{5}$ PL transition intensity reached a maximum value at $5.02 \mathrm{Mol} \% \mathrm{~Tb}^{3+}$ in electrodeposited thin films of $\mathrm{Y}_{2} \mathrm{O}_{3}$. The particle size of the crystallites in their films was not indicated. In the case of

${ }^{\mathrm{z}}$ E-mail: terry.ireland@brunel.ac.uk
CL, concentration quenching started at lower $\mathrm{Tb}^{3+}$ concentration; we found that the CL lumen efficacy of $1 \% \mathrm{Y}_{2} \mathrm{O}_{3}: \mathrm{Tb}^{3+}$ is higher than that of $3 \% \mathrm{Y}_{2} \mathrm{O}_{3}: \mathrm{Tb}^{3+} .{ }^{1}$ Obviously, the results of Muenchausen et al. ${ }^{5}$ and Wang et al. ${ }^{6}$ are contradictory; therefore, we cannot draw conclusions on possible differences between concentration quenching of $\mathrm{Y}_{2} \mathrm{O}_{3}: \mathrm{Tb}^{3+}$ in PL and in CL.

The excitation spectra of $\mathrm{Y}_{2} \mathrm{O}_{3}: \mathrm{RE}^{3+}\left(\mathrm{RE}^{3+}\right.$ being a trivalent rare earth ion) were presented by Kano in the Phosphor Handbook. ${ }^{7}$ The excitation band of $\mathrm{Y}_{2} \mathrm{O}_{3}: \mathrm{Tb}^{3+}$ represented in Kano's chapter shows two peaks, one at $304 \mathrm{~nm}$ and the other at $280 \mathrm{~nm}$; however, it is not indicated which transitions were used to monitor these excitation spectra. Other reports on the excitation spectrum of $\mathrm{Y}_{2} \mathrm{O}_{3}: \mathrm{Tb}^{3+}$ were given by Ropp, ${ }^{8}$ Najafov et al., ${ }^{4}$ Muenchausen et al., ${ }^{5}$ Meng et al., ${ }^{9}$ Liu et al., ${ }^{10}$ Ray et al., ${ }^{11}$ Loitongbam et al. ${ }^{12}$ and Som et al. ${ }^{13}$ Most authors assigned the broad excitation band between $260 \mathrm{~nm}$ and $310 \mathrm{~nm}$ to a $4 \mathrm{f}^{8} \rightarrow 4 \mathrm{f}^{7} 5 \mathrm{~d}^{1}$ transition in the $\mathrm{Tb}^{3+}$ ion. Only Ray et al. ${ }^{11}$ and Loitongbam et al. ${ }^{12}$ designated this excitation band as a charge transfer $(\mathrm{CT})$ band. A third possibility, direct $\mathrm{Tb}^{3+}$ excitation through a $4 \mathrm{f}^{8} \rightarrow 4 \mathrm{f}^{8}$ transition, was mentioned by Som et al. ${ }^{13}$ We shall adopt here the assignment of Kano: ${ }^{7}$ the excitation band between $260 \mathrm{~nm}$ and $340 \mathrm{~nm}$ is due to $4 \mathrm{f}^{8} \rightarrow 4 \mathrm{f}^{7} 5 \mathrm{~d}^{1}$ transitions, since the CT band of $\mathrm{Y}_{2} \mathrm{O}_{3}: \mathrm{Tb}^{3+}$ is positioned at $64000 \mathrm{~cm}^{-1}(156 \mathrm{~nm})$ in the VUV. These assignments were confirmed by Dorenbos, see for instance Ref. 14 and publications cited in this recent paper. No attention was paid in the papers ${ }^{3-6,8-13}$ to symmetry-related transitions and effects in the spectrum of $\mathrm{Y}_{2} \mathrm{O}_{3}: \mathrm{Tb}^{3+}$, mainly because the lines at $542 \mathrm{~nm}$ and $544 \mathrm{~nm}$ in the emission PL spectra were not observed as split (due to poor resolution of the spectrometers) or their behavior was overlooked and thus, not taken into consideration. Laser-excited spectra of photonic bandgap $\mathrm{Y}_{2} \mathrm{O}_{3}: \mathrm{Tb}^{3+}$ material were reported by Withnall et al. ${ }^{15}$ in a temperature range from $25-400^{\circ} \mathrm{C}$. These temperatures were too high to split the $\mathrm{Y}_{2} \mathrm{O}_{3}: \mathrm{Tb}^{3+5} \mathrm{D}_{4} \rightarrow{ }^{7} \mathrm{~F}_{5}$ doublets at $542 \mathrm{~nm}$ and $544 \mathrm{~nm}$.

\section{Materials and Methods}

The synthesis of nanosized cubic $\mathrm{Y}_{2} \mathrm{O}_{3}: \mathrm{Tb}^{3+}$ particles (in-house) has been described in detail in Part 1. Figure 1 shows panchromatic STEM images of the CL emitted by $0.1 \% \mathrm{Y}_{2} \mathrm{O}_{3}: \mathrm{Tb}^{3+}$ at $-171.3^{\circ} \mathrm{C}$ and beam energy of $200 \mathrm{keV}$ and $10 \% \mathrm{Y}_{2} \mathrm{O}_{3}: \mathrm{Tb}^{3+}$ at room temperature and $80 \mathrm{keV}$. The particle size varied from 130 to $200 \mathrm{~nm}$ in the $0.1 \%$ sample, but was much smaller in the $10 \%$ sample. It can be seen that the particles consist of smaller crystallites, which have dimensions of about $40 \mathrm{~nm}$. In Part 1, we presented images of $\mathrm{Y}_{2} \mathrm{O}_{3}: \mathrm{Tb}^{3+}$ particles at other $\mathrm{Tb}^{3+}$ concentration. 


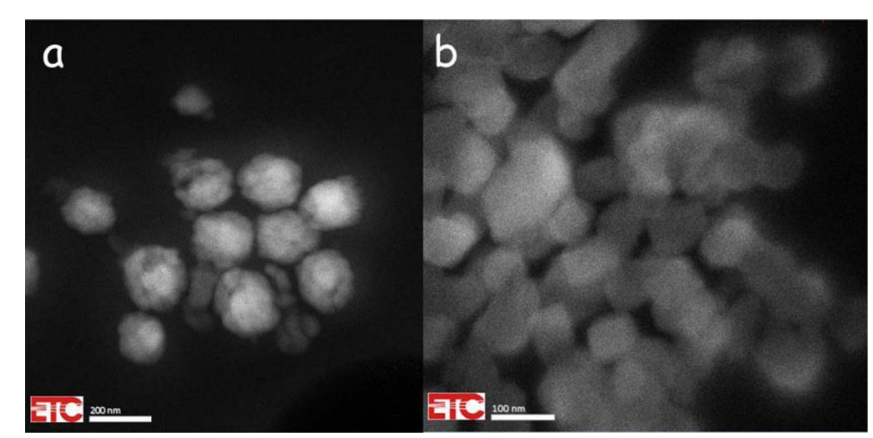

Figure 1. Panchromatic images of $\mathrm{Y}_{2} \mathrm{O}_{3}: \mathrm{Tb}^{3+}$ recorded with Vulcan detector of STEM. a: $0.1 \% \mathrm{Y}_{2} \mathrm{O}_{3}: \mathrm{Tb}^{3+}$ at $-171^{\circ} \mathrm{C}$ and $200 \mathrm{keV}$. b: $10 \% \mathrm{Y}_{2} \mathrm{O}_{3}: \mathrm{Tb}^{3+}$ at room temperature and $80 \mathrm{keV}$.

PL emission spectra of the $\mathrm{Y}_{2} \mathrm{O}_{3}: \mathrm{Tb}^{3+}$ samples were measured with a Bentham phosphor spectrometer system (Bentham Instruments Ltd., Reading, UK), configured with M300 excitation and emission monochromators and equipped with $0.37 \mathrm{~mm}$ slits. The resolution of the spectrometer was insufficient to detect the doublet structure of the strong emission lines at 542.5 and $544.2 \mathrm{~nm} .{ }^{1}$ The absolute wavelength calibration of this emission monochromator could be off by maximally $0.4 \mathrm{~nm}$; however, relative wavelength values were accurate within $0.3 \mathrm{~nm}$. All PL spectra were recorded at room temperature. The minimum wavelength in the excitation spectra was $250 \mathrm{~nm}$.

Figures $1 \mathrm{a}$ and $1 \mathrm{~b}$ are panchromatic CL images recorded with a STEM, model 2100F, JEOL, Japan, equipped with a Vulcan CL detector, Gatan, USA, for imaging and spectroscopic purposes. Details of this equipment were also described in Part 1.

\section{Results}

Figure 2 is an overlay of two PL spectra of $1 \% \mathrm{Y}_{2} \mathrm{O}_{3}: \mathrm{Tb}^{3+}$ between 460 and $700 \mathrm{~nm}$ : one excited at $282 \mathrm{~nm}$ and the other excited at $305 \mathrm{~nm}$. The ${ }^{5} \mathrm{D}_{4} \rightarrow{ }^{7} \mathrm{~F}_{\mathrm{J}}(\mathrm{J}=1,2 \ldots 6)$ transition clusters are indicated in Figure 2. The weak emission lines of the ${ }^{5} \mathrm{D}_{4} \rightarrow{ }^{7} \mathrm{~F}_{2}$ transition cluster are noticeable at $\sim 666 \mathrm{~nm}$, even the weaker lines of the ${ }^{5} \mathrm{D}_{4} \rightarrow{ }^{7} \mathrm{~F}_{1}$ transition cluster at $\sim 688 \mathrm{~nm}$ can be observed. The spectra excited at $282 \mathrm{~nm}$ and $305 \mathrm{~nm}$ are different, although not so noticeable in Figure 2. In the next figures the relevant differences will be magnified. Exciting cubic $\mathrm{Y}_{2} \mathrm{O}_{3}: \mathrm{Tb}^{3+}$ with radiation between $260 \mathrm{~nm}$ and $285 \mathrm{~nm}$ wavelength results in mainly $\mathrm{C}_{2}$ type emission lines, whereas excitation at $305 \mathrm{~nm}$ results in the $\mathrm{C}_{3 \mathrm{i}}$ type emission lines becoming more visible. This can be seen in Figure 3 for the ${ }^{5} \mathrm{D}_{4} \rightarrow{ }^{7} \mathrm{~F}_{5}$ transition cluster. This symmetry-related assignment is based on the analyses of the CL spectra reported in Part 1: the peak at $542.5 \mathrm{~nm}$ was identified as $\mathrm{C}_{2}$ and the peak at $544.2 \mathrm{~nm}$ as $\mathrm{C}_{3 \mathrm{i}}$. The spectra in Figure 3



Figure 2. PL spectra of $1 \% \mathrm{Y}_{2} \mathrm{O}_{3}: \mathrm{Tb}^{3+}$ excited at 282 and $305 \mathrm{~nm}$.



Figure 3. Overlay of PL spectra of ${ }^{5} \mathrm{D}_{4} \rightarrow{ }^{7} \mathrm{~F}_{5}$ transition cluster of $0.3 \%$ $\mathrm{Y}_{2} \mathrm{O}_{3}: \mathrm{Tb}^{3+}$ excited at $260 \mathrm{~nm}, 285 \mathrm{~nm}$ and $305 \mathrm{~nm}$. The CL spectrum of $0.7 \% \mathrm{Y}_{2} \mathrm{O}_{3}: \mathrm{Tb}^{3+}$ was recorded in the TEM at beam energy of $80 \mathrm{keV}$ and temperature of $103 \mathrm{~K}$. The peaks between $540 \mathrm{~nm}$ and $545 \mathrm{~nm}$ in the CL spectrum have been labeled for deconvolution purposes.

have been normalized to the highest peak in each spectrum to enhance the visibility of the differences. Exciting $0.3 \% \mathrm{Y}_{2} \mathrm{O}_{3}: \mathrm{Tb}^{3+}$ between $260 \mathrm{~nm}$ and $285 \mathrm{~nm}$ enhances the peak at $542.5 \mathrm{~nm}$ rather than the peak at $544.2 \mathrm{~nm}$, whereas excitation at $305 \mathrm{~nm}$ reverses the outcome. The CL spectrum recorded at low temperature shows that the peaks at $542.5 \mathrm{~nm}$ and $544.2 \mathrm{~nm}$ are doublets.

Excitation spectra of $\mathrm{Y}_{2} \mathrm{O}_{3}: \mathrm{Tb}^{3+}$ monitored at various emission peaks are represented in Figure 4. The spectra shown in Figures 4a and $4 \mathrm{~b}$ are quite different at low $\mathrm{Tb}^{3+}$ concentrations, whilst at high $\mathrm{Tb}^{3+}$ concentration they show a tendency to become more equal. In Figure $4 \mathrm{a}$ the maximum is at about $282 \mathrm{~nm}$, while Figure $4 \mathrm{~b}$ shows a maximum at $305 \mathrm{~nm}$. The excitation spectrum of $10 \% \mathrm{Y}_{2} \mathrm{O}_{3}: \mathrm{Tb}^{3+}$ manifests a small absorption band at $338 \mathrm{~nm}$, which is not noticeable in the spectra of the other $\mathrm{Y}_{2} \mathrm{O}_{3}: \mathrm{Tb}^{3+}$ samples. The excitation spectrum of $\mathrm{Y}_{2} \mathrm{O}_{3}: \mathrm{Tb}^{3+}$ has weaker bands in the range $340 \mathrm{~nm}<\lambda<$ $500 \mathrm{~nm}$ (where $\lambda$ is wavelength), as illustrated in Figures $4 \mathrm{c}$ and $4 \mathrm{~d}$. In Figure $4 \mathrm{c}$ a tentative assignment of some bands has been indicated. There seems to be no symmetry-related effect in Figure 4c. Figure 4d shows the excitation spectra when monitoring at the $629.8 \mathrm{~nm}$ and $621.5 \mathrm{~nm}$ peaks of the ${ }^{5} \mathrm{D}_{4} \rightarrow{ }^{7} \mathrm{~F}_{3}$ transition cluster. These peaks have been assigned as $\mathrm{C}_{3 \mathrm{i}}$ and $\mathrm{C}_{2}$ type transitions respectively in Part 1, and their behavior in PL spectra will be shown hereafter. Between $460 \mathrm{~nm}$ $<\lambda<500 \mathrm{~nm}$, the bands of the top and bottom spectra in Figure 4d appear at the same wavelength, between $380 \mathrm{~nm}<\lambda<460 \mathrm{~nm}$ the peaks of the top spectrum have got a blueshift with respect to those in the bottom spectrum. Although we did not assign the transitions of those peaks, we assume that corresponding bands belong to the same transitions and that the shift between the upper and lower spectrum is caused by $\mathrm{Tb}^{3+}$ located at $\mathrm{C}_{3 \mathrm{i}}$ sites (bottom) and $\mathrm{Tb}^{3+}$ located at $\mathrm{C}_{2}$ sites (top).

The excitation spectra represented in Figures $4 \mathrm{a}$ and $4 \mathrm{~b}$ can be deconvoluted with two Gaussian profiles, E1 and E2, as shown in Figures $5 \mathrm{a}$ and $5 \mathrm{~b}$. The algorithm for a Gaussian-type deconvolution has been described in Part 1 and will not be repeated here. The Gaussian profiles were fitted to the experimental spectra with a least squares algorithm. Lorentzian profiles did not yield a satisfactory fit, because these profiles are too broad at low values of the spectral absorption and yielded least squares sums that were about 100 times larger than those for the Gaussian profiles. The E1-peak is broader than the E2 peak. Najafov et al. ${ }^{4}$ and Som et al. ${ }^{12}$ also made a Gaussian deconvolution of the excitation band for $\mathrm{Y}_{2} \mathrm{O}_{3}: \mathrm{Tb}^{3+}$ between $250 \mathrm{~nm}$ and $340 \mathrm{~nm}$. They also found that the E2 peak was narrower than the E1peak. Som et al. ${ }^{12}$ estimated the full width at half maximum (FWHM) of $\mathrm{E} 1$ and $\mathrm{E} 2$ at $0.45 \mathrm{eV}$ and $0.26 \mathrm{eV}$ respectively. These values are smaller than our results, which are $0.58 \mathrm{eV}$ and $0.29 \mathrm{eV}$. In Figure 6 we have plotted the ratio between the integrated absorptions (IA) of $\mathrm{E} 1$ and $\mathrm{E} 2$, viz. $\mathrm{IA}_{\mathrm{E} 1} / \mathrm{IA} \mathrm{E}_{\mathrm{E} 2}$, as a function of the $\mathrm{Tb}^{3+}$ concentration. 

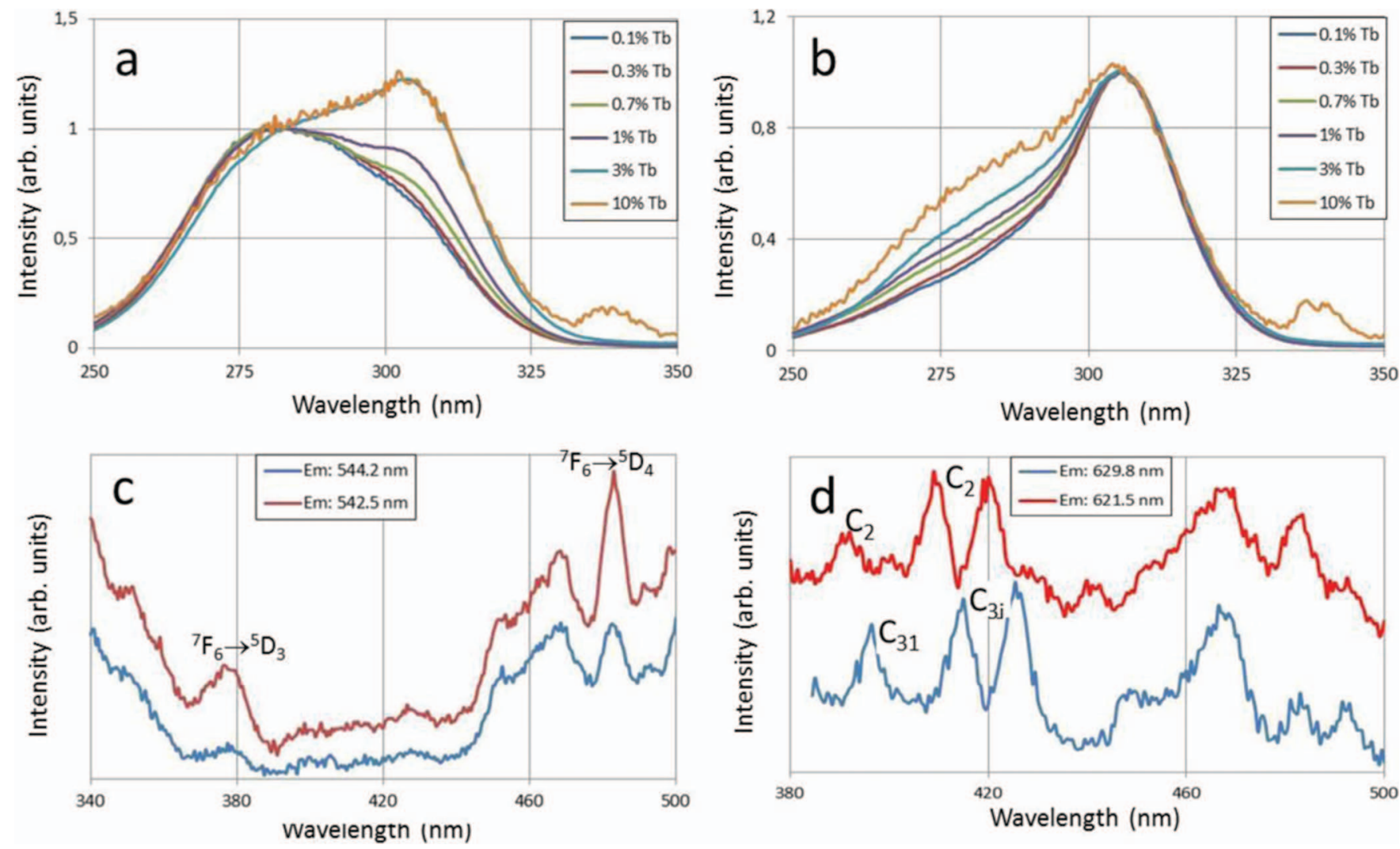

Figure 4. Excitation spectra of $\mathrm{Y}_{2} \mathrm{O}_{3}: \mathrm{Tb}^{3+}$ a: monitored at $542.5 \mathrm{~nm}$. b: monitored at $544.2 \mathrm{~nm}$. c: $3 \% \mathrm{Y}_{2} \mathrm{O}_{3}: \mathrm{Tb}^{3+}$ between 340 and $500 \mathrm{~nm}$. d: $1 \% \mathrm{Y}_{2} \mathrm{O}_{3}: \mathrm{Tb}^{3+}$ between 380 and $500 \mathrm{~nm}$.

Integrated absorption refers to the area under the $\mathrm{E} 1$ or $\mathrm{E} 2$ peaks. We assign the E1 peak in Figure 5 to the ${ }^{7} \mathrm{~F}_{6} \rightarrow{ }^{9} \mathrm{D}_{\mathrm{J}}\left(\mathrm{C}_{2}\right)$ excitation and the E2 peak to the ${ }^{7} \mathrm{~F}_{6} \rightarrow{ }^{9} \mathrm{D}_{\mathrm{J}}\left(\mathrm{C}_{3 \mathrm{i}}\right)$ excitation, in which the ${ }^{9} \mathrm{D}_{\mathrm{J}}$ levels have the $4 f^{7} 5 d^{1}$ electron configuration. This issue will be considered in more detail in the Discussion section. In the case of monitoring the emission at the $\mathrm{C}_{3 \mathrm{i}}$-transtion at $544.2 \mathrm{~nm}$ (line $\mathrm{B}$ ) we see a slight increase of the E1-peak $\left(\mathrm{C}_{2}\right.$-type $)$ with $\mathrm{Tb}^{3+}$ concentration in Figure $4 \mathrm{~b}$ and Figure 6. Figure 4a shows an increase of $\mathrm{C}_{3 \mathrm{i}}$-characteristics with $\mathrm{Tb}^{3+}$ concentration, which is also clearly reflected in Figure 6 by the negative slope of line $\mathrm{A}$, indicating the decreasing $\mathrm{IA}_{\mathrm{E} 1} / \mathrm{IA} \mathrm{E}_{\mathrm{E} 2}$ ratio monitored at $542.5 \mathrm{~nm}$.

PL spectra of the ${ }^{5} \mathrm{D}_{4} \rightarrow{ }^{7} \mathrm{~F}_{5}$ transition cluster are depicted in Figure 7: Figure 7a shows the spectra excited at $282 \mathrm{~nm}$, while Figure $7 \mathrm{~b}$ shows the spectra excited at $305 \mathrm{~nm}$. For comparison reasons these spectra are normalized: at $542.5 \mathrm{~nm}$ for Figure $7 \mathrm{a}$ and at $544.2 \mathrm{~nm}$ for
Figure $7 \mathrm{~b}$. The differences between the spectra in Figures $7 \mathrm{a}$ and $7 \mathrm{~b}$ are striking: Figure 7a does not show large differences between the normalized spectra, whereas the differences in Figure $7 \mathrm{~b}$ are large. The peak at $544.2 \mathrm{~nm}$ is not the only one that shows $\mathrm{C}_{3 \mathrm{i}}$ character, the peaks at $548.1 \mathrm{~nm}, 550.3 \mathrm{~nm}$ and $552 \mathrm{~nm}$ also show $\mathrm{C}_{3 \mathrm{i}}$ character, albeit less than the peak at $544.2 \mathrm{~nm}$. This can be concluded from the variations shown in Figure $7 \mathrm{~b}$. The symmetry-related effects as shown in Figure 7 are most pronounced for the ${ }^{5} \mathrm{D}_{4} \rightarrow{ }^{7} \mathrm{~F}_{5}$ transition cluster, for the other transition clusters these are less. Figure 8 shows $\mathrm{PL}$ spectra of the ${ }^{5} \mathrm{D}_{4} \rightarrow{ }^{7} \mathrm{~F}_{3}$ transition cluster of $\mathrm{Y}_{2} \mathrm{O}_{3}: \mathrm{Tb}^{3+}$ between $610 \mathrm{~nm}$ and $640 \mathrm{~nm}$, being the second transition cluster that shows clear concentration effects, which we interpret as symmetry-related effects. It can be seen that the peaks at $629.8 \mathrm{~nm}$ and $637 \mathrm{~nm}$ have $\mathrm{C}_{3 \mathrm{i}}$ character, because these peaks decrease with respect to the other peaks at high $\mathrm{Tb}^{3+}$ concentration when excited at $305 \mathrm{~nm}$. A similar
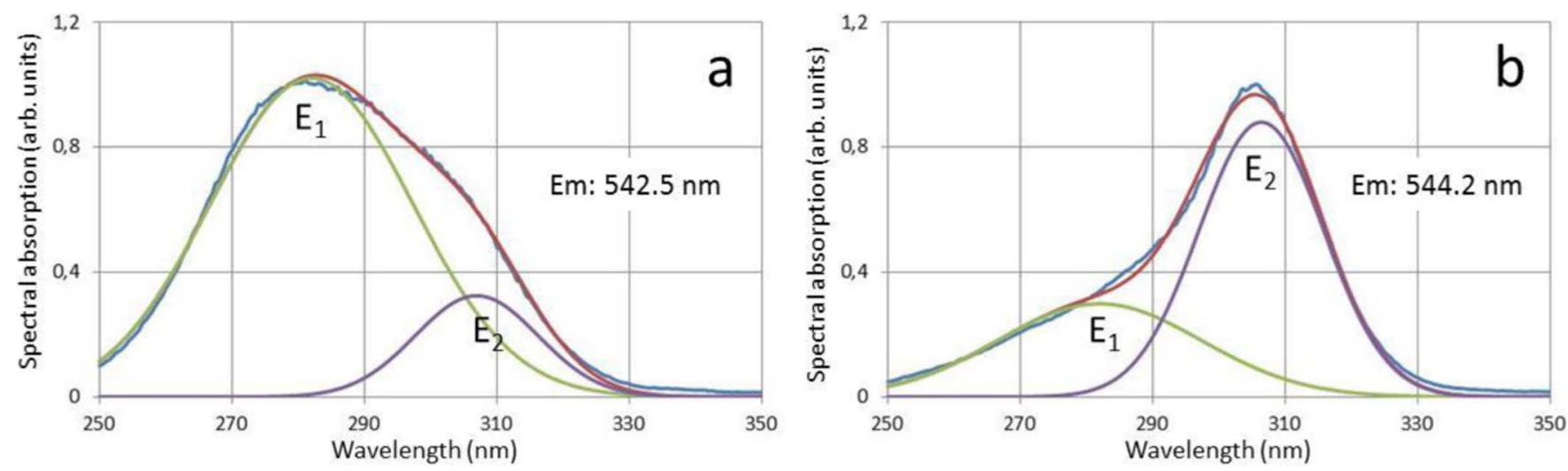

Figure 5. Deconvolution of excitation spectra of $0.1 \% \mathrm{Y}_{2} \mathrm{O}_{3}: \mathrm{Tb}^{3+}$; a: $\mathrm{C}_{2}$-type spectrum, monitored at $542.5 \mathrm{~nm}$; b: $\mathrm{C}_{3 \mathrm{i}}$-type spectrum, monitored at $544.2 \mathrm{~nm}$. 




Figure 6. Ratio of integrated absorption (IA) of peaks E1 and E2 in the excitation spectra of $\mathrm{Y}_{2} \mathrm{O}_{3}: \mathrm{Tb}^{3+}$. Line A refers to the excitation spectra monitored at $542.5 \mathrm{~nm}$, while line B refers to the excitation spectra monitored at $544.2 \mathrm{~nm}$.

conclusion was drawn after analyzing the CL spectra of the ${ }^{5} \mathrm{D}_{4} \rightarrow{ }^{7} \mathrm{~F}_{3}$ transition cluster of $\mathrm{Y}_{2} \mathrm{O}_{3}: \mathrm{Tb}^{3+}$ in Part 1 (Figure $5 \mathrm{c}$ ). ${ }^{1}$ The PL spectra of the ${ }^{5} \mathrm{D}_{4} \rightarrow{ }^{7} \mathrm{~F}_{6}$ and ${ }^{5} \mathrm{D}_{4} \rightarrow{ }^{7} \mathrm{~F}_{4}$ transition clusters of $\mathrm{Y}_{2} \mathrm{O}_{3}: \mathrm{Tb}^{3+}$ do not have strong isolated $\mathrm{C}_{3 \mathrm{i}}$ type peaks. At room temperature the $\mathrm{C}_{3 \mathrm{i}}$ type peaks are overlapped by stronger $\mathrm{C}_{2}$ type peaks in these clusters. The spectra of $10 \% \mathrm{Y}_{2} \mathrm{O}_{3}: \mathrm{Tb}^{3+}$ are noisy because of concentration quenching, which yields a low luminous efficiency. Because of the 7 to 10 times weaker emission peaks in the ${ }^{5} \mathrm{D}_{4} \rightarrow{ }^{7} \mathrm{~F}_{3}$ transition cluster than those in the ${ }^{5} \mathrm{D}_{4} \rightarrow{ }^{7} \mathrm{~F}_{5}$ transition cluster, we did not analyze the phenomena shown in Figure 8.

The analysis of the concentration effect shown in Figure $7 \mathrm{~b}$ requires a deconvolution of the measured spectra. This deconvolution has now been done with Lorentzian profiles. Gaussian profiles have been used in Part 1, because at that time it was not clear that the $542.5 \mathrm{~nm}$ and $544.2 \mathrm{~nm}$ peaks were doublets, as shown in Figure 3. The consequence is that a better representation is obtained with Lorentzian profiles that are narrow at spectral radiances $>$ half maximum and broad at the bottom.

The spectral radiance $\operatorname{SR}(\lambda)$, where $\lambda$ represents the wavelength of a Lorentzian profile, can be written as:

$$
S R(\lambda)=\sum_{i} \frac{A_{i}}{1+\frac{\left(\lambda-\lambda_{i}\right)^{2}}{s_{i}^{2}}},
$$

where $A_{i}$ is the maximum spectral radiance of the $i^{\text {th }}$ peak, $\lambda_{i}$ is the wavelength at the maximum, $s_{i}$ is the half width at half maximum and the radiance $\mathrm{R}_{\mathrm{i}}$ of the $\mathrm{i}^{\text {th }}$ transition is

$$
R_{i}=\int_{-\infty}^{\infty} \frac{A_{i} d \lambda}{1+\frac{\left(\lambda-\lambda_{i}\right)^{2}}{s_{i}^{2}}}=A_{i} s_{i} \pi .
$$

An example of the deconvolution of the ${ }^{5} \mathrm{D}_{4} \rightarrow{ }^{7} \mathrm{~F}_{5}$ peaks at $542.5 \mathrm{~nm}$ and $544.2 \mathrm{~nm}$ is shown in Figure 9 for $1 \% \mathrm{Y}_{2} \mathrm{O}_{3}: \mathrm{Tb}^{3+}$. In this deconvolution seven Lorentzian profiles were used. The width parameter
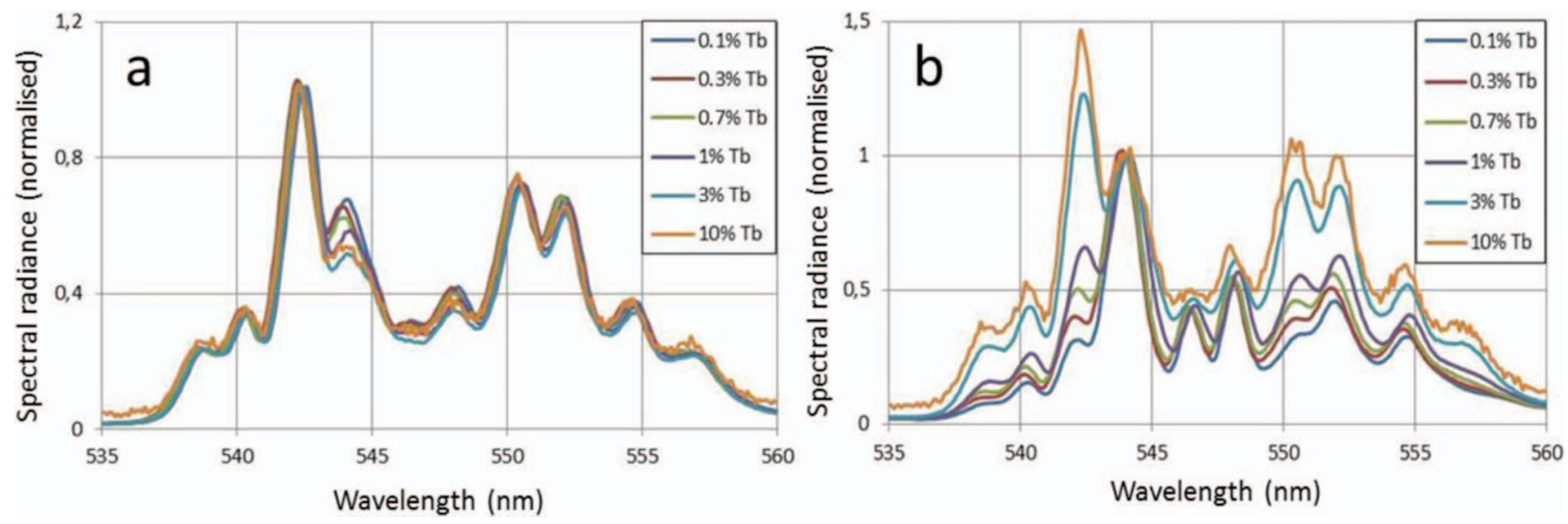

Figure 7. PL spectra of the ${ }^{5} \mathrm{D}_{4} \rightarrow{ }^{7} \mathrm{~F}_{5}$ transition cluster of $\mathrm{Y}_{2} \mathrm{O}_{3}: \mathrm{Tb}^{3+}$ at various $\mathrm{Tb}^{3+}$ concentrations. a: Excited at $282 \mathrm{~nm}$ and normalized at $542.5 \mathrm{~nm}$. b: Excited at $305 \mathrm{~nm}$ and normalized at $544.2 \mathrm{~nm}$.
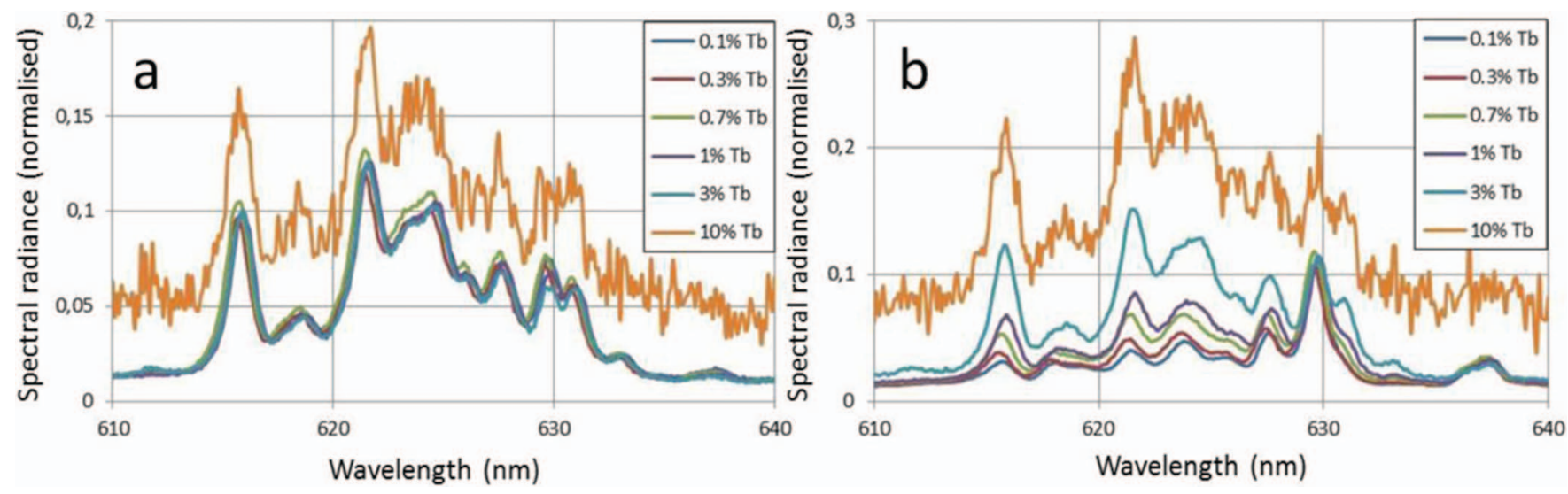

Figure 8. PL spectra of the ${ }^{5} \mathrm{D}_{4} \rightarrow{ }^{7} \mathrm{~F}_{3}$ cluster of $\mathrm{Y}_{2} \mathrm{O}_{3}: \mathrm{Tb}^{3+}$ at various $\mathrm{Tb}^{3+}$ concentrations. a: Excited at $282 \mathrm{~nm}$ and normalized at $542.5 \mathrm{~nm}$. b: Excited at $305 \mathrm{~nm}$ and normalized at $544.2 \mathrm{~nm}$. 


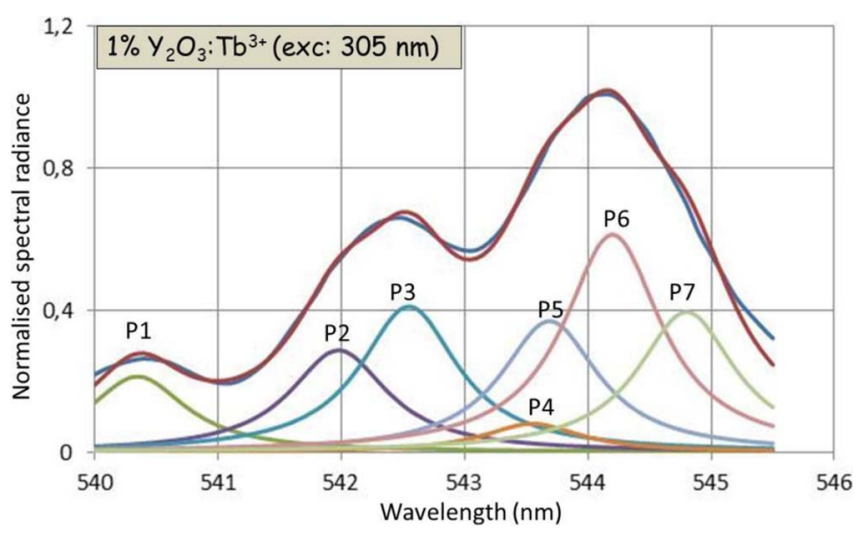

Figure 9. Deconvolution of a part of the ${ }^{5} \mathrm{D}_{4} \rightarrow{ }^{7} \mathrm{~F}_{5}$ spectrum between 540 and $546 \mathrm{~nm}$ with seven Lorentzian profiles (p1, p2, . p7).

$s_{i}$ was set equal for these seven peaks and the peak wavelengths $\lambda_{i}$ were fitted manually. The amplitudes $A_{i}$ were fitted to the measured PL spectrum with a least squares algorithm using Microsoft's Excel Solver software.

The seven Lorentzian profiles that represent the measured spectrum are indicated in Figure 9 as p1, p2,...p7. The most relevant are p2, p3, $\mathrm{p} 5$ and $\mathrm{p} 6$, because the radiances of these peaks are used for further analyses.

The radiance ratio $R_{p 3} / R_{p 6}$ has been plotted in Figure 10 as a function of the $\mathrm{Tb}^{3+}$ concentration in a double log plot. Plots of $\mathrm{R}_{\mathrm{p} 2} / \mathrm{R}_{\mathrm{p} 5}$ or $\left(\mathrm{R}_{\mathrm{p} 2}+\mathrm{R}_{\mathrm{p} 3}\right) /\left(\mathrm{R}_{\mathrm{p} 5}+\mathrm{R}_{\mathrm{p} 6}\right)$ versus $\mathrm{Tb}^{3+}$ concentration yield almost the same results and will not be considered here. Figure 10 summarizes the most important results of the PL and CL spectra of $\mathrm{Y}_{2} \mathrm{O}_{3}: \mathrm{Tb}^{3+}$. Curve $A$ is based on the PL spectra excited at $305 \mathrm{~nm}$. This curve shows the largest variation of $R_{p 3} / R_{p 6}$ versus $\mathrm{Tb}^{3+}$ concentration. Line $B$ is based on the PL spectra excited at $282 \mathrm{~nm}$ and shows a limited variation. Curve $\mathrm{C}$ in Figure 10 is based on the CL spectra recorded with the spectrometer connected to the TEM at $200 \mathrm{keV}$ and $-170^{\circ} \mathrm{C}$ as shown in Figure 11b; this will be discussed in the next paragraphs. Curve D, copied from Part 1, is based on the CL-spectra recorded at $15 \mathrm{keV}$ at room temperature. Curves $\mathrm{A}, \mathrm{C}$ and $\mathrm{D}$ show a knee at about $0.7 \%$ $\mathrm{Tb}^{3+}$. In Part 1 a relation between the average distance $\mathrm{D}_{\mathrm{Tb}}$ between two $\mathrm{Tb}^{3+}$ ions in the $\mathrm{Y}_{2} \mathrm{O}_{3}$ lattice and the $\mathrm{Tb}^{3+}$ concentration has been given. At $0.7 \mathrm{Mol} \% \mathrm{~Tb}^{3+} \mathrm{D}_{\mathrm{Tb}}$ is $1.7 \mathrm{~nm}$, hence from the PL spectra excited at $305 \mathrm{~nm}$ we also find that the critical distance, $D_{T b^{3+}}^{\text {Crit }}$, for interaction between the $\mathrm{C}_{3 \mathrm{i}}$ and $\mathrm{C}_{2}$ sites is $1.7 \mathrm{~nm}$. It is expected that line $\mathrm{B}$ does not show any concentration dependence. However, Figure 5 shows that when irradiating $\mathrm{Y}_{2} \mathrm{O}_{3}: \mathrm{Tb}^{3+}$ at $282 \mathrm{~nm}$ also some



Figure 10. Plot of $R_{p 3} / R_{p 6}$ as a function of $\mathrm{Tb}^{3+}$ concentration. Curve A: PL data of Figure 7b, Line B: PL data of Figure 7a, Curve C: CL data at $200 \mathrm{keV}$ and $\mathrm{T}=103 \mathrm{~K}$ (Figure $11 \mathrm{~b}$ ), Curve D: CL data at $15 \mathrm{keV}$ and $\mathrm{T}=300 \mathrm{~K}$ (from Part $1^{1}$ ).

energy will be absorbed by $\mathrm{Tb}^{3+}$ at $\mathrm{C}_{3 \mathrm{i}}$-sites (E2-band). This explains why line $B$ is not flat.

We have presented preliminary measurements of the CL spectra of $3 \% \mathrm{Y}_{2} \mathrm{O}_{3}: \mathrm{Tb}^{3+}$, which have been recorded with the Vulcan CL detector of the TEM at various temperatures in Part 1. We have now extended these measurements to other concentrations and the results are presented in Figures 11 and 12. Notwithstanding long integration times of about $500 \mathrm{~s}$, the spectra of the ${ }^{5} \mathrm{D}_{4} \rightarrow{ }^{7} \mathrm{~F}_{5}$ transition cluster of $\mathrm{Y}_{2} \mathrm{O}_{3}: \mathrm{Tb}^{3+}$ are quite noisy. The temperatures indicated in Figure $11 \mathrm{a}$ refer to thermocouple readings of the sample holder. It is assumed that the temperatures of the holder and that of the phosphor particles on the C-grid are identical. We shall come back to this assumption in the Discussion section. The spectra of the ${ }^{5} \mathrm{D}_{4} \rightarrow{ }^{7} \mathrm{~F}_{\mathrm{J}}(\mathrm{J} \neq 5)$ transition clusters were too weak to be recorded. Figure 11a illustrates the increased splitting of the doublets centered at $542.5 \mathrm{~nm}$ and $544.2 \mathrm{~nm}$ that is observed at low temperature, presumably because of lower levels of vibronic broadening. Furthermore, the doublet peak centered at $542.2 \mathrm{~nm}$ increases with respect to that centered at $544 \mathrm{~nm}$ when the temperature is increased. Figure $11 \mathrm{~b}$ shows a similar trend: the doublet at $542.2 \mathrm{~nm}$ increases, while the doublet at $544 \mathrm{~nm}$ decreases when the concentration of $\mathrm{Tb}^{3+}$ in the $\mathrm{Y}_{2} \mathrm{O}_{3}$ lattice is raised. It can be seen in Figure $11 \mathrm{~b}$ that the $542.5 \mathrm{~nm}$ and $544.2 \mathrm{~nm}$ transitions are clearly split at $-170{ }^{\circ} \mathrm{C}$ for all concentrations $\left(10 \% \mathrm{Y}_{2} \mathrm{O}_{3}: \mathrm{Tb}^{3+}\right.$ has not been indicated in Figure 11b).

In order to quantify the effects depicted in Figure 11, the spectra need to be deconvoluted. This was achieved with seven Lorentzian
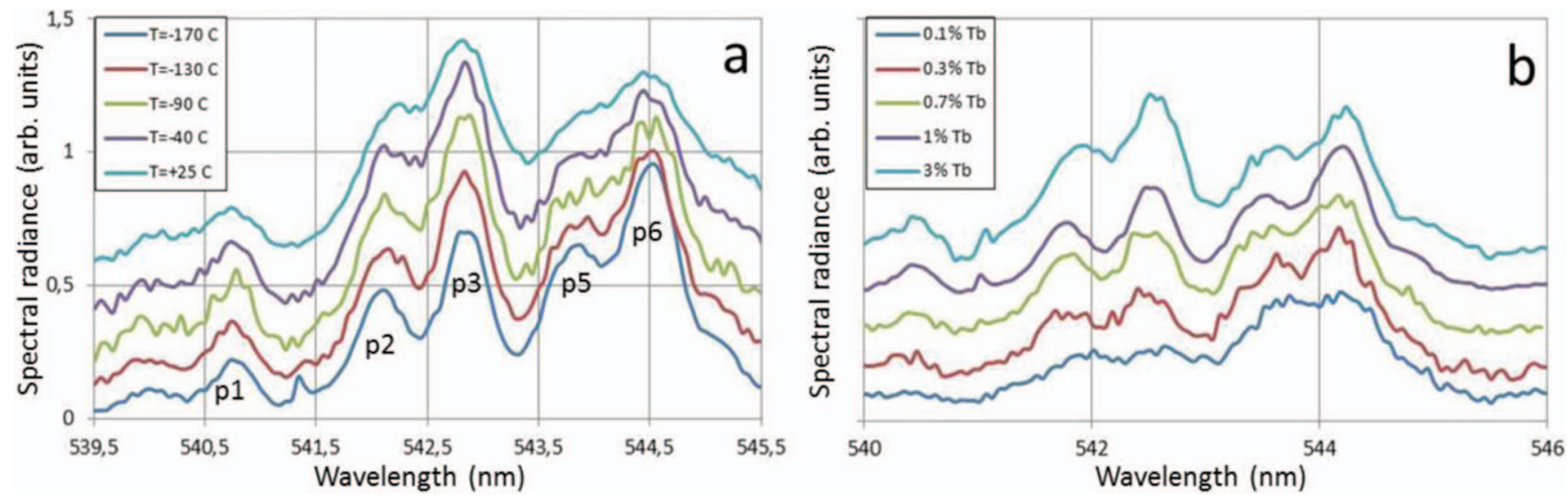

Figure 11. CL spectra of recorded at $200 \mathrm{keV}$ with Vulcan CL detector. a: Spectra of $1 \% \mathrm{Y}_{2} \mathrm{O}_{3}: \mathrm{Tb}^{3+}$ at various temperatures. b: Spectra at $-170^{\circ} \mathrm{C}$ and various $\mathrm{Tb}^{3+}$ concentrations. Spectra have been shifted vertically to improve clarity. 




Figure 12. Arrhenius plot of $R_{p 3} / R_{p 6}$.

profiles using the same algorithm as described above. Gaussian profiles were inadequate in this case. The full width half maximum (FWHM), being $2 \mathrm{~s}_{\mathrm{i}}$ for a Lorentzian profile, increases almost linearly with temperature from $0.56 \mathrm{~nm}$ at $-170^{\circ} \mathrm{C}$ to $0.88 \mathrm{~nm}$ at $25^{\circ}$ $\mathrm{C}$ for $0.3 \% \mathrm{Y}_{2} \mathrm{O}_{3}: \mathrm{Tb}^{3+}$. For reasons of identification the peaks in Figure 11a have been numbered in the same way as those in Figures 3 and 9. Figure 12 shows an Arrhenius plot of $R_{p 3} / R_{p 6}$, being the ratio of the radiances of the peaks p3 and p6, as indicated in Figures 9 and 11a. The activation energy for the ratio $R_{p 3} / R_{p 6}$ is indicated in the table combined with Figure 12. From this table we estimate that the average activation energy is $0.007 \mathrm{eV}$.

As mentioned above, curve $\mathrm{C}$ in Figure 10 is based on the $\mathrm{CL}$ spectra depicted in Figure 11b. This curve refers to a temperature of $103 \mathrm{~K}$. Although the knee is less pronounced than that in curve A, these two curves indicate the same trend and support the foregoing conclusion on the value of the critical distance, $D_{T b^{3+}}^{C r i t}$, for interaction between the $\mathrm{C}_{3 \mathrm{i}}$ and $\mathrm{C}_{2}$ sites in $\mathrm{Y}_{2} \mathrm{O}_{3}: \mathrm{Tb}^{3+}$. It is worth noting that the ratio $\mathrm{R}_{\mathrm{p} 3} / \mathrm{R}_{\mathrm{p} 6}$ that can be derived from the $\mathrm{CL}$ spectrum shown in Figure 3 does not agree with the ratio for the $0.7 \% \quad \mathrm{Y}_{2} \mathrm{O}_{3}: \mathrm{Tb}^{3+}$ material that has been derived from Figure $11 \mathrm{~b}$. The reason is that in recording the CL spectrum shown in Figure 3 the beam energy in the TEM was lowered from $200 \mathrm{keV}$ to $80 \mathrm{keV}$ in order to get a less noisy spectrum. In doing so, the $\mathrm{Y}_{2} \mathrm{O}_{3}: \mathrm{Tb}^{3+}$ saturated: $\mathrm{Tb}^{3+}$ ions at $\mathrm{C}_{3 \mathrm{i}}$ sites were more seriously affected by saturation than $\mathrm{Tb}^{3+}$ ions at $\mathrm{C}_{2}$ sites. The same phenomenon has been described in Part 1 by excitation at
$5 \mathrm{keV}$ and changing the current density. The trend of the CL spectra shown in Figure 11b corresponds to the sequence shown in Figure 5a of Part 1, thus, it can be concluded that the TEM spectra in Figure 11b refer to the non-saturated condition.

\section{Discussion}

First the energy transfer from $\mathrm{Tb}^{3+}$ at a $\mathrm{C}_{3 \mathrm{i}}$ lattice site to $\mathrm{Tb}^{3+}$ at a $\mathrm{C}_{2}$ lattice site will be considered. For this purpose we have depicted in Figure 13 the energy levels based on the assignments for the excitation bands between $250 \mathrm{~nm}$ and $340 \mathrm{~nm}$ and the strongest emission peaks in the ${ }^{5} \mathrm{D}_{4} \rightarrow{ }^{7} \mathrm{~F}_{5}$ transition cluster of $\mathrm{Y}_{2} \mathrm{O}_{3}: \mathrm{Tb}^{3+}$. Figure $13 \mathrm{a}$ is an overall picture, whereas Figure $13 \mathrm{~b}$ zooms in on the main peaks of the ${ }^{5} \mathrm{D}_{4} \rightarrow{ }^{7} \mathrm{~F}_{5}$ transition cluster. In the following analysis it is assumed that excited energy levels of $\mathrm{Tb}^{3+}$ in the $\mathrm{Y}_{2} \mathrm{O}_{3}$ lattice are not saturated; saturation will be considered in the second half of this section. Based on the analyses of the CL spectra of $\mathrm{Y}_{2} \mathrm{O}_{3}: \mathrm{Eu}^{3+},{ }^{2}$ we have assigned the $542.4 \mathrm{~nm}$ and $544.2 \mathrm{~nm}$ peaks in the spectrum of $\mathrm{Y}_{2} \mathrm{O}_{3}: \mathrm{Tb}^{3+}$ as $\mathrm{C}_{2}$ and $\mathrm{C}_{3 \mathrm{i}}$ respectively in Part 1 . It is tempting to make the same assignment for the excitation spectrum, viz. the peaks E1 and E2 in Figure 5. In doing so, E1 would represent a $\mathrm{C}_{2}$ excitation peak and E2 a $\mathrm{C}_{3 \mathrm{i}}$ peak, as mentioned before.

The crystal field splitting of the ${ }^{9} \mathrm{D}_{\mathrm{J}}$ level for the $4 \mathrm{f}^{7} 5 \mathrm{~d}^{1}$ electron configuration of $\mathrm{Tb}^{3+}$ in $\mathrm{Y}_{2} \mathrm{O}_{3}$ is much larger than that for the $4 \mathrm{f}^{8}$ configuration. This explains the broadening of the E1 and E2 peaks

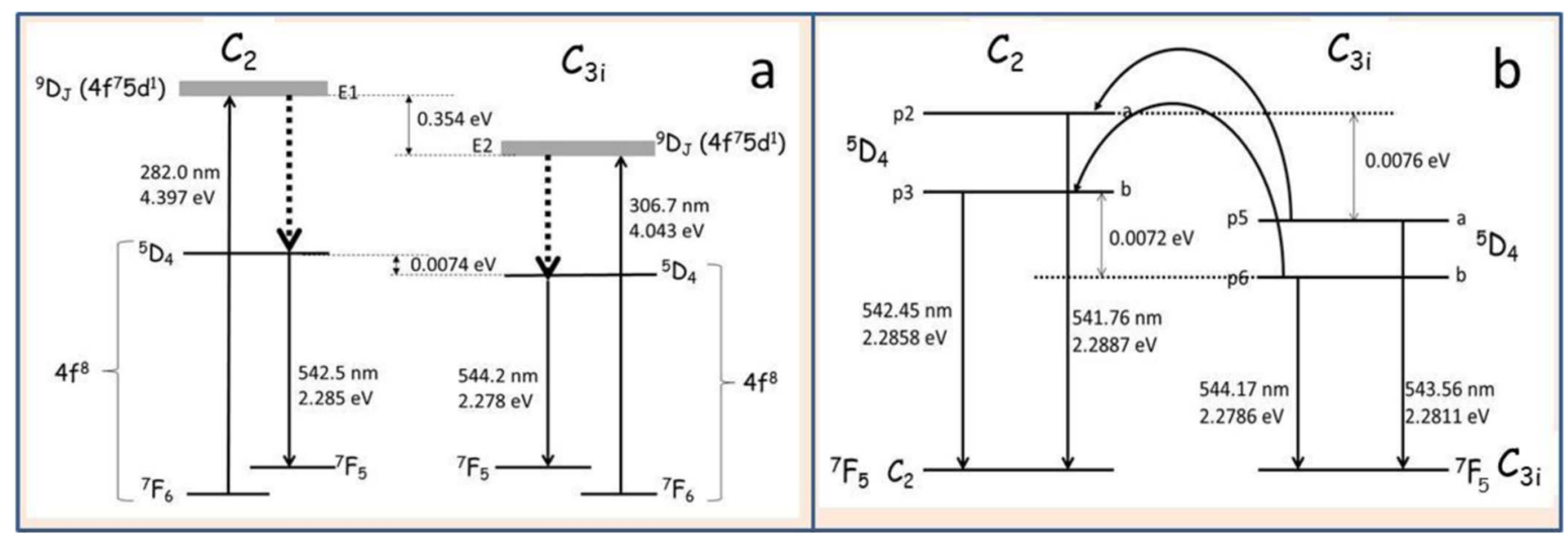

Figure 13. Energy levels involved in the excitation band and ${ }^{5} \mathrm{D}_{4} \rightarrow{ }^{7} \mathrm{~F}_{5}$ transition cluster of $\mathrm{Y}_{2} \mathrm{O}_{3}: \mathrm{Tb}^{3+}$. a: Excitation mechanism; E1 and E2 refer to the peaks shown in Figure 5. b: Energy transfer from ${ }^{5} \mathrm{D}_{4}\left(\mathrm{C}_{3 \mathrm{i}}\right)$ to ${ }^{5} \mathrm{D}_{4}\left(\mathrm{C}_{2}\right)$. For reasons of clarity the energy scale has been distorted. 
in the excitation spectra represented in Figures 4 and 5 as compared to the narrow $4 \mathrm{f}^{8} \rightarrow 4 \mathrm{f}^{8}$ transitions shown in Figures 2 and 3 . This broadening is also indicated in Figure $13 \mathrm{a}$ by the broad ${ }^{9} \mathrm{D}_{\mathrm{J}}$ levels for the $\mathrm{C}_{2}$ and $\mathrm{C}_{3 \mathrm{i}}$ symmetry. After excitation to one of the ${ }^{9} \mathrm{D}_{\mathrm{J}}$ levels, energy trickles via radiationless energy loss processes down to the ${ }^{5} \mathrm{D}_{4}$ $\left(\mathrm{C}_{2}\right)$ or ${ }^{5} \mathrm{D}_{4}\left(\mathrm{C}_{3 \mathrm{i}}\right)$ levels respectively. At sufficiently high temperatures and close distances between $\mathrm{Tb}^{3+}$ at $\mathrm{C}_{3 \mathrm{i}}$ lattice sites and $\mathrm{Tb}^{3+}$ at $\mathrm{C}_{2}$ lattice sites (or high $\mathrm{Tb}^{3+}$ concentration), energy may be transferred as indicated in Figure 13b. This will occur between the two ${ }^{5} \mathrm{D}_{4}$ levels, because the energy separation is only $0.0074 \mathrm{eV}$, whereas the energy difference between the two ${ }^{9} \mathrm{D}_{\mathrm{J}}$ levels is $0.354 \mathrm{eV}$. The Arrhenius type analysis of the radiance ratio between $\mathrm{p} 3$ and p6, shown in Figure 12, is a confirmation of this conclusion: the activation energy of 0.007 $\mathrm{eV}$ is identical to the energy difference between the ${ }^{5} \mathrm{D}_{4}\left(\mathrm{C}_{2}\right)$ and ${ }^{5} \mathrm{D}_{4}$ $\left(\mathrm{C}_{3 \mathrm{i}}\right)$ levels indicated in Figure 13b. The energy difference between p5 and p2 is $0.0076 \mathrm{eV}$ and between p6 and p3 it is $0.0072 \mathrm{eV}$, being only slightly different from the average difference indicated in Figure 13a. From the Arrhenius type analysis, we can exclude $\mathrm{p} 6 \rightarrow \mathrm{p} 2$ and $\mathrm{p} 5 \rightarrow \mathrm{p} 3$ uplifting schemes, because these have quite different energy separations.

The next issue to consider is the shape of the excitation band of cubic nanosized $\mathrm{Y}_{2} \mathrm{O}_{3}: \mathrm{Tb}^{3+}$ between $250 \mathrm{~nm}$ and $340 \mathrm{~nm}$ shown in Figure 4 . Based on the variation of the height of this excitation band as a function of particle size, Meng et al. ${ }^{8}$ concluded that this band is a $4 \mathrm{f}^{8} \rightarrow 4 \mathrm{f}^{7} 5 \mathrm{~d}^{1}$ transition. The spectra recorded by Meng et al. did not show a change of the relative heights of the constituting peaks E1 and E2 as a function of particle size. The FWHM values of the excitation peaks E1 and E2 as measured by us are $0.58 \mathrm{eV}$ and $0.28 \mathrm{eV}$ respectively. These values are about two orders of magnitude larger than the FWHMs of the $4 \mathrm{f}^{8} \rightarrow 4 \mathrm{f}^{8}$ emission peaks, for example the FWHM of the p6 peak $(544.4 \mathrm{~nm})$ at room temperature is $0.004 \mathrm{eV}$. The FWHMs of the excitation band in $\mathrm{Y}_{2} \mathrm{O}_{3}: \mathrm{Tb}^{3+}$ resemble those of the $4 \mathrm{f}^{8} \rightarrow 4 \mathrm{f}^{7} 5 \mathrm{~d}^{1}$ transitions in $\mathrm{BaF}_{2}: \mathrm{Tb}^{3+16}$ and thus, this agrees with the $4 \mathrm{f}^{8} \rightarrow 4 \mathrm{f}^{7} 5 \mathrm{~d}^{1}$ assignment suggested by $\mathrm{Kano}^{7}$ and Dobrowolska et al. ${ }^{14}$

A feature that not has been reported previously is that the excitation band between $250 \mathrm{~nm}$ and $340 \mathrm{~nm}$ of $\mathrm{Y}_{2} \mathrm{O}_{3}: \mathrm{Tb}^{3+}$ shows symmetryrelated effects, just like the emission peaks at $542.5 \mathrm{~nm}$ and $544.2 \mathrm{~nm}$ of the ${ }^{5} \mathrm{D}_{4} \rightarrow{ }^{7} \mathrm{~F}_{5}$ transition cluster. This raises the question what is the correspondence of the change of the peak ratios indicated in Figures 6 and 10. Figure 6 shows two lines, $A$ and B, referring to different monitoring transitions. Unlike Figure 6, curves A, C and D in Figure 10 show a knee, from which the critical distance of energy flow from $\mathrm{Tb}^{3+}$ at a $\mathrm{C}_{3 \mathrm{i}}$ lattice to $\mathrm{Tb}^{3+}$ at a $\mathrm{C}_{2}$ lattice site has been derived. When monitoring the excitation energy at the $542.5 \mathrm{~nm}$ peak $\left(\mathrm{C}_{2}\right)$ one has to realize that at high $\mathrm{Tb}^{3+}$ concentration a part of the energy will come from $\mathrm{Tb}^{3+}$ at $\mathrm{C}_{3 \mathrm{i}}$ lattice sites according to the mechanism shown in Figure 13b. This explains the negative slope of line A depicted in Figure 6. Line B in this graph has a positive slope. When monitoring the emission at the $544.2 \mathrm{~nm}$ peak $\left(\mathrm{C}_{3 \mathrm{i}}\right)$ we have some interference from the p3 peak at $542.5 \mathrm{~nm}$ at high $\mathrm{Tb}^{3+}$ concentration, as shown in Figure 9. Since p3 $\left(\mathrm{C}_{2}\right.$-type $)$ will increase with the $\mathrm{Tb}^{3+}$ concentration, as shown in Figure $7 \mathrm{~b}$, the overlap with the p5-p6 $\left(\mathrm{C}_{3 \mathrm{i}}\right.$-type $)$ peak will increase as well. This explains the increase of the $\mathrm{C}_{2}$ content (or positive slope) of line $\mathrm{B}$ in Figure 6, because unambiguous monitoring of $\mathrm{C}_{2}$ or $\mathrm{C}_{3 \mathrm{i}}$ transitions is not possible due to interferences from overlapping peaks. This overlapping argument is irrelevant for line A, because both Figure $7 \mathrm{a}$ and line B in Figure 10 indicate that the heights of the $542.5 \mathrm{~nm}$ and $544.2 \mathrm{~nm}$ peaks change only slightly as a function of the $\mathrm{Tb}^{3+}$ concentration. Conversely, the limited variation of $R_{p 3} / R_{p 6}$ (line $B$ ) in Figure 10 is an indication that energy is transferred from $\mathrm{Tb}^{3+}$ at $\mathrm{C}_{3 \mathrm{i}}$ sites to $\mathrm{Tb}^{3+}$ at $\mathrm{C}_{2}$ sites and not vice versa. Curve $A$ in Figure 10 shows a larger variation of $R_{p 3} / R_{p 6}$ versus $T b^{3+}$ concentration than the CL-based curves $\mathrm{C}$ and $\mathrm{D}$. This is caused by the specific excitation of $\mathrm{Tb}^{3+}$ at $\mathrm{C}_{3 \mathrm{i}}$-sites for curve $\mathrm{A}$, whereas in the case of curves $\mathrm{C}$ and $\mathrm{D}$ the $\mathrm{Y}_{2} \mathrm{O}_{3}$ lattice is excited and the energy flows to $\mathrm{Tb}^{3+}$ at both $\mathrm{C}_{2}-$ and $\mathrm{C}_{3 \mathrm{i}}$-sites: hence, the variation of $\mathrm{R}_{\mathrm{p} 3} / \mathrm{R}_{\mathrm{p} 6}$ is less.

Saturation of the $544.2 \mathrm{~nm}$ peak $\left(\mathrm{C}_{3 \mathrm{i}}\right)$ at continuous irradiation of an electron beam was discussed in Part 1 in terms of the classical theory of Bril and Kröger. ${ }^{17}$ For reasons of completeness we shall reproduce a part of those arguments here. At high current densities $j$ the radiance $R_{i}$ of transition $i$ can be written as

$$
R_{i}(j)=\frac{j \eta_{i}}{1+j \eta_{i} \tau_{i} / N_{i}}
$$

where $\eta_{i}$ is the efficiency of transition i at low current density, $\tau_{i}$ is the 1/e decay time of transition $\mathrm{i}$ and $\mathrm{N}_{\mathrm{i}}$ is the number of $\mathrm{Tb}^{3+}$ ions per $\mathrm{cm}^{3}$ at a $\mathrm{C}_{2}$ or $\mathrm{C}_{3 \mathrm{i}}$ lattice site. In this analysis $\mathrm{i}=\mathrm{p} 3$ or $\mathrm{p} 6$, because within the accuracy limit of the deconvolutions the ratios $\mathrm{p} 2 / \mathrm{p} 3$ and $\mathrm{p} 5 / \mathrm{p} 6$ are constant and the ratio between the radiance of the $\mathrm{C}_{2}$ and $\mathrm{C}_{3 \mathrm{i}}$ type transition can well be represented by $\mathrm{R}_{\mathrm{p} 3} / \mathrm{R}_{\mathrm{p} 6}$. When at (very) large current density the second term in the denominator becomes larger than 1, then Eq. 3 can be simplified to

$$
R_{i}=\frac{N_{i}}{\tau_{i}}
$$

Eq. 4 represents the saturation limit, in which the radiance is no longer a function of the current density. There are three times more $\mathrm{Tb}^{3+}$ ions at $\mathrm{C}_{2}$ sites than at $\mathrm{C}_{3 \mathrm{i}}$ sites, $\tau_{\mathrm{p} 6}=5.8 \mathrm{~ms}$ and $\tau_{\mathrm{p} 3}=1.7 \mathrm{~ms}$ at $0.7 \%$ $\mathrm{Y}_{2} \mathrm{O}_{3}: \mathrm{Tb}^{3+},{ }^{1}$ thus, the ratio $\mathrm{R}_{\mathrm{p} 3} / \mathrm{R}_{\mathrm{p} 6}$ at saturation for this $\mathrm{Tb}^{3+}$ concentration becomes 10 . In other words, the $\mathrm{C}_{3 \mathrm{i}}$ type transition would be dwarfed as compared to its $\mathrm{C}_{2}$ companion. In the CL spectra described in Part 1, we have not measured such large differences between the radiances of these two peaks at current densities up to $5 \mathrm{~mA} / \mathrm{cm}^{2}$. The current densities in scanning electron microscopes are much larger than $5 \mathrm{~mA} / \mathrm{cm}^{2}$ as discussed ${ }^{2}$ and if the kinetic energy of the electrons would completely be absorbed by the phosphor particles, these latter would evaporate. Fortunately, at $200 \mathrm{keV}$ more than $99 \%$ of the beam energy passes the nanosized phosphor particles. If saturation would be the case, the ratio $R_{p 3} / R_{p 6}$ must be large at small $\mathrm{Tb}^{3+}$ concentration and will decrease at larger concentrations. Since the opposite is observed, as shown in Figures 10 (CL-curve) and 11b, it can be concluded that saturation may be ruled out at beam energy of $200 \mathrm{keV}$. From the CL spectrum of $0.7 \% \mathrm{Y}_{2} \mathrm{O}_{3}: \mathrm{Tb}^{3+}$ represented in Figure 3, which was recorded at $80 \mathrm{keV}$, it can be seen that the ratio $\mathrm{R}_{\mathrm{p} 3} / \mathrm{R}_{\mathrm{p} 6}$ differs substantially from the value for $0.7 \% \mathrm{Y}_{2} \mathrm{O}_{3}: \mathrm{Tb}^{3+}$ as represented in Figure $11 \mathrm{~b}$. At this condition we cannot rule out saturation. The penetration depth at electron energy of $80 \mathrm{keV}$ is still much larger than the phosphor particle size; however, the time of contact between beam electrons and lattice ions is longer than at $200 \mathrm{keV}$, which enables stronger interaction and more energy transfer from the E-beam to the phosphor. From the foregoing reasoning it can be concluded as a side note that current density does not seem the obvious criterion for studying phosphor saturation in a scanning electron microscope: other properties of the E-beam need to be considered to enable quantitative analyses.

Besides saturation there is another mechanism that might explain the odd ratio $R_{p 3} / R_{p 6}$ in the CL spectrum depicted in Figure 3, viz. energy transfer from a $\mathrm{Tb}^{3+}$ ion at a $\mathrm{C}_{3 \mathrm{i}}$ site to $\mathrm{Tb}^{3+}$ at a $\mathrm{C}_{2}$ site. In the previous section it has been assumed that the temperatures of the phosphor particles and holder are identical; however, at high energy transfer from E-beam to phosphor target this assumption is not particularly likely. If at $80 \mathrm{keV}$ more energy from the E-beam is transferred to the phosphor particles than at $200 \mathrm{keV}$, the phosphor particles may be heated and according to the Arrhenius plot shown in Figure 12 this would result in more energy transfer from $C_{3 i}$ to $C_{2}$. From the measured ratios $\mathrm{R}_{\mathrm{p} 3} / \mathrm{R}_{\mathrm{p} 6}$ for $0.7 \% \mathrm{Y}_{2} \mathrm{O}_{3}: \mathrm{Tb}^{3+}$ at $80 \mathrm{keV}$ and $200 \mathrm{keV}$ the temperature in the phosphor particles bombarded with $80 \mathrm{keV}$ electrons can be calculated from the average activation energy of $0.007 \mathrm{eV}$. The phosphor temperature would be between $-30{ }^{\circ} \mathrm{C}$ and $-10{ }^{\circ} \mathrm{C}$ : much higher than the holder, which is at $-170^{\circ} \mathrm{C}$. From our results it cannot be concluded which mechanism is most likely: saturation or energy transfer from $\mathrm{C}_{3 \mathrm{i}}$ to $\mathrm{C}_{2}$. It is probable that both mechanisms play a role.

For comparison reasons we present in Figure 14 the excitation spectra of cubic nanosized $\mathrm{Y}_{2} \mathrm{O}_{3}: \mathrm{Eu}^{3+}$ monitored at $611 \mathrm{~nm}$ and $582 \mathrm{~nm}$ : the transition at $611 \mathrm{~nm}$ has $\mathrm{C}_{2}$ symmetry, while the weak transition at $582 \mathrm{~nm}$ has $\mathrm{C}_{3 \mathrm{i}}$ symmetry. ${ }^{2}$ It can be seen that the $\mathrm{C}_{2}$ 




Figure 14. Excitation spectra of nanosized cubic $1 \% \mathrm{Y}_{2} \mathrm{O}_{3}: \mathrm{Eu}^{3+}$ at $25^{\circ} \mathrm{C}$ monitored at $611 \mathrm{~nm}\left(\mathrm{C}_{2}\right)$ and $582 \mathrm{~nm}\left(\mathrm{C}_{3 \mathrm{i}}\right)$. Spectra have been normalized at $260 \mathrm{~nm}$.

and $\mathrm{C}_{3 \mathrm{i}}$ CT-bands of $\mathrm{Y}_{2} \mathrm{O}_{3}: \mathrm{Eu}^{3+}$ at about $260 \mathrm{~nm}$ are equal. The back ground level in the $\mathrm{C}_{3 \mathrm{i}}$-type spectrum recorded at $582 \mathrm{~nm}$ is higher, because this transition is much weaker than the $611 \mathrm{~nm}$ transition. Unlike Figure 4, which refers to $\mathrm{Y}_{2} \mathrm{O}_{3}: \mathrm{Tb}^{3+}$, Figure 14 shows that it is impossible to excite symmetry-related energy levels in $\mathrm{Y}_{2} \mathrm{O}_{3}: \mathrm{Eu}^{3+}$ by irradiation with UV light at wavelengths between $250 \mathrm{~nm}$ and $300 \mathrm{~nm}$.

\section{Conclusions}

The PL and CL spectra of cubic nanosized $\mathrm{Y}_{2} \mathrm{O}_{3}: \mathrm{Tb}^{3+}$ show differences as a function of $\mathrm{Tb}^{3+}$ concentration and temperature. We have interpreted these differences in terms of symmetry-related effects: viz. $\mathrm{Tb}^{3+}$ at $\mathrm{C}_{2}$ and $\mathrm{C}_{3 \mathrm{i}}$ lattice sites of cubic $\mathrm{Y}_{2} \mathrm{O}_{3}$. From our analyses it can be concluded that at high $\mathrm{Tb}^{3+}$ concentrations and temperatures higher than $100 \mathrm{~K}$, excitation energy will be transferred via radiationless processes from $\mathrm{Tb}^{3+}$ at $\mathrm{C}_{3 \mathrm{i}}$ lattice sites to $\mathrm{Tb}^{3+}$ at $\mathrm{C}_{2}$ lattice sites. This energy transfer occurs from the ${ }^{5} \mathrm{D}_{4}\left(\mathrm{C}_{3 \mathrm{i}}\right)$ to the ${ }^{5} \mathrm{D}_{4}\left(\mathrm{C}_{2}\right)$ level.
Perhaps surprisingly for such a well-known phosphor, we did not find symmetry-related analyses of the CL and PL spectra of $\mathrm{Y}_{2} \mathrm{O}_{3}: \mathrm{Tb}^{3+}$ in the literature.

\section{Acknowledgments}

We are grateful to the EPSRC and the Technology Strategy Board (TSB) for funding the PURPOSE (TP11/MFE/6/I/AA129F; EPSRC TS/G000271/1) and CONVERTED (JeS no. TS/1003053/1) programs. We are also grateful to the TSB for funding the CONVERT program.

\section{References}

1. D. den Engelsen, P. G. Harris, T. G. Ireland, G. Fern, and J. Silver, ECS J. Solid State Sci. Technol., 4, R105 (2015).

2. D. den Engelsen, P. G. Harris, T. G. Ireland, and J. Silver, ECS J. Solid State Sci. Technol., 4, R1 (2015).

3. H. Song and J. Wang, J. Lumin., 118, 220 (2006).

4. H. Najafov, Y. Satoh, S. Ohshio, A. Kato, and H. Saitoh, Jpn. J. Appl. Phys., 43, 7111 (2004).

5. R. E. Muenchausen, L. G. Jacobsohn, B. L. Bennett, E. A. McKigney, J. F. Smith, J. A. Valdez, and D. W. Cooke, J. Lumin., 126, 838 (2007).

6. L. Wang, N. Liao, L. Shi, H. Jia, P. Du, Z. Xi, and D. Jin, Electrochem. Solid State Lett., 13, E7 (2010).

7. T. Kano in Phosphor Handbook, 2nd ed., W. Yen, S. Shionoya, and H. Yamamoto eds., p. 197, CRC Press, Boca Raton (2007).

8. R. C. Ropp, J. Electrochem. Soc., 111, 311 (1964).

9. Q. Meng, B. Chen, W. Xu, Y. Yang, X. Zhao, W. Di, S. Lu, X. Wang, J. Sun, L. Cheng, T. Yu, and Y. Peng, J. Appl. Phys., 102, 093505 (2007).

10. Z. Liu, L. Yu, Q. Wang, Y. Tao, and H. Yang, J. Lumin., 131, 12 (2011).

11. S. Ray, A. Patra, and P. Pramanik, Opt. Mater, 30, 608 (2007).

12. R. S. Loitongbam, W. R. Singh, G. Phaomei, and N. S. Singh, J. Lumin., 140, 95 (2013).

13. S. Som, S. Dutta, Vijay Kumar, Vinod Kumar, H. C. Swart, and S. K. Sharma, J. Lumin., 146, 162 (2014).

14. A. Dobrowolska, E. C. Karsu, A. J. J. Bos, and P. Dorenbos, J. Lumin., 160, 321 (2015).

15. R. Withnall, M. I. Martinez-Rubio, G. R. Fern, T. G. Ireland, and J. Silver, J. Opt. A: Pure Appl. Opt., 5, S81 (2003).

16. M. E. Witkowski and A. J. Wojtowicz, Optical Mater, 33, 1535 (2011).

17. A. Bril and F. A. Kröger, Philips Tech. Rev., 12, 120 (1950). 